\title{
Surgical repair for persistent truncus arteriosus in neonates and older children
}

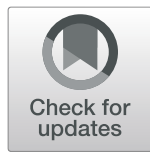

\author{
Rawan M. Alamri ${ }^{1 \dagger}$, Ahmed M. Dohain ${ }^{2,3 \dagger}$, Amr A. Arafat ${ }^{4 \dagger}$, Ahmed F. Elmahrouk ${ }^{4,5^{*}}$ (D, Abdullah H. Ghunaim ${ }^{1}$,
} Ahmed A. Elassal ${ }^{1,6}$, Ahmed A. Jamjoom ${ }^{5}$ and Osman O. Al-Radi ${ }^{1,5}$

\begin{abstract}
Objectives: Persistent truncus arteriosus represents less than $3 \%$ of all congenital heart defects. We aim to analyze mid-term outcomes after primary Truncus arteriosus repair at different ages and to identify the risk factors contributing to mortality and the need for intervention after surgical repair.

Methods: This retrospective cohort study included 36 children, underwent repair of Truncus arteriosus in the period from January 2011 to December 2018 in two institutions. We recorded the clinical and echocardiographic data for the patients preoperatively, early postoperative, 6 months postoperative, then every year until their last documented follow-up appointment.

Results: Thirty-six patients had truncus arteriosus repair during the study period. Thirty-one patients had open sternum post-repair, and two patients required extracorporeal membrane oxygenation. Bleeding occurred in 15 patients (41.67\%), and operative mortality occurred in 5 patients (14.7\%). Patients with truncus arteriosus type 2 $(p=0.008)$ and $3(p=0.001)$ and who were ventilated preoperatively $(p<0.001)$ had a longer hospital stay. Surgical re-intervention was required in 8 patients (22.86\%), and 11 patients (30.56\%) had catheter-based reintervention. Freedom from reintervention was $86 \%$ at 1 year, $75 \%$ at 2 years and $65 \%$ at 3 years. Survival at 1 year was $81 \%$ and at 3 years was $76 \%$. High postoperative inotropic score predicted mortality $(p=0.013)$.

Conclusion: Repair of the truncus arteriosus can be performed safely with low morbidity and mortality, both in neonates, infants, and older children. Re-intervention is common, preferably through a transcatheter approach.
\end{abstract}

Keywords: Persistent truncus arteriosus, Surgical outcome, Late presentation

\section{Introduction}

Truncus arteriosus (TA) represents less than 3\% of all congenital heart defects. It is characterized by a common arterial trunk that arises from the base of the heart and supplies systemic, coronary, and pulmonary circulation.1,2 It is associated with ventricular septal defect

\footnotetext{
* Correspondence: Ael-Mahrouk@KFSHRC.edu.sa; A_marouky@hotmail.com; Ahmed.elmahrouki1@med.tanta.edu.eg

${ }^{\dagger}$ Rawan Alamri, Ahmed Dohain and Amr A. Arafat contributed equally to this work.

${ }^{4}$ Department of Cardiothoracic Surgery, Tanta University, Tanta, Egypt

${ }^{5}$ Department of Cardiothoracic Surgery, King Faisal Specialist Hospital and Research Centre, Jeddah, Saudi Arabia

Full list of author information is available at the end of the article
}

(VSD) and sometimes, other cardiac lesions such as interrupted aortic arch (IAA), truncal valve stenosis (or regurgitation), and/or hypoplasia of the pulmonary artery branches $[1-3]$.

The treatment of choice of TA, during the neonatal period, in the current era is primary repair $[4,5]$. This involves separating the pulmonary and systemic pathways through the establishment of a right ventricle to pulmonary artery connection along with VSD closure [6].

Previous studies have identified IAA and moderate to severe truncal valve regurgitation to be risk factors influencing the mortality after TA repair $[1,6-9]$. 
The Society of Thoracic Surgeons Congenital Heart Surgery Database reported surgical mortality of $9.2 \%$ in children and $10.8 \%$ in neonates after TA repair [10, 11]. The mortality beyond surgical hospitalization was reported to range from 2 to $15 \%$, according to singlecenter studies that followed patients for 2-24 years after surgery $[2,7,8,12]$.

Almost all right ventricle to pulmonary artery (RV-PA) conduits require interventions later in life, and it is considered to be the main source of long-term morbidity $[12,13]$.

Currently, there is no consensus on the optimal conduit that can be used for TA repair [13]. Late presentation of children with TA may make surgery more complicated or even contraindicated due to elevated pulmonary vascular resistance (PVR) [14]. Without surgical intervention, $80 \%$ of these patients die within the first year of life, mainly during early infancy $[5,8,15]$.

We aim to analyze mid-term outcomes after primary TA repair at different ages and to identify the risk factors contributing to mortality and the need for intervention after surgical repair.

\section{Patients and methods}

\section{Study population}

We retrospectively reviewed the data for all patients who underwent surgical repair of TA from January 2011 to December 2018 at King Abdulaziz University Hospital (KAUH) and King Faisal Specialized Hospital, Jeddah, Saudi Arabia. Approval of the study was obtained from the Institutional Research Ethical Board, and the requirement for individual consent was waived for this retrospective observational study.

\section{Definitions and clinical data collection}

The modified Collett and Edward classification was used to categorizing patients into three subtypes: In type I, the main pulmonary artery (PA) arises from anterior/lateral aspect of the arterial trunk and then branches into the left and right pulmonary arteries. In type II, PA branches originate separate but adjacent from the posterior/lateral aspect of the trunk. In type III, PA branches arise independently from the sides of the common trunk. We excluded the rare type IV from the study, as it is considered, now, a form of pulmonary atresia $[16,17]$.

Early mortality was defined as death within 30 days of operation or before hospital discharge. Death after that time was considered as late mortality.

We collected the relevant data associated with the initial surgical repair, including demographics, baseline characteristics, operative, and postoperative variables. The clinical outcome measures were recorded, including postoperative mortality, complications, requirement of extracorporeal membrane oxygenation (ECMO) support, duration of mechanical ventilation, vasoactive inotropic score (VIS), intensive care unit (ICU) stay, hospital stay, reoperation, and cardiac catheterization intervention. Excessive bleeding was defined as $7 \mathrm{~mL} / \mathrm{kg} / \mathrm{h}$ or more for 2 or more consecutive hours in the first 12 post- operative hours, $84 \mathrm{~mL} / \mathrm{kg}$ or more total for the first 24 postoperative hours, or surgical re-exploration for bleeding or cardiac tamponade physiology in the first 24 postoperative hours. VIS was calculated by the following formula using drug dosage in $\mathrm{mcg} / \mathrm{kg} / \mathrm{min}$ : (dopamine + dobutamine $)+($ milrinone $\times 10)+($ epinephrine $\times$

$100)+($ norepinephrine $\times 100)$ [16]

Preoperative cardiac catheterization was performed for patients who were presented late to evaluate PA pressure and pulmonary vascular resistance index (PVRi). The operability of those patients was determined with the clinical manifestations, chest radiography, echocardiography, and hemodynamic data obtained from cardiac catheterization. Surgical repair was considered if PVRi was less than 8 Wood units [18].

\section{Surgical procedure}

The surgery was performed on the cardio-pulmonary bypass (CBP) through a median sternotomy for all patients. After disconnecting the pulmonary arteries (PAs) from the common trunk, the infundibulum of the right ventricle (RV) was incised, and the VSD was closed with a pericardial patch or a synthetic (Gore-Tex) patch, using an interrupted suture technique. The aortic wall defect was closed directly or repaired with an autologous pericardial patch or bovine pericardial patch.

Continuity between the RV and PA was established with either a bovine jugular valve conduit or an aortic (or pulmonary) homograft. Both truncal and tricuspid valves were routinely inspected, and the appropriate repair was performed if necessary. Additional procedures as IAA repair were performed before reconstruction of the right ventricular outflow tract (RVOT).

The atrial septum was left open if the intraoperative PA pressure was more than $80 \%$ of the systemic pressure before weaning from $\mathrm{CPB}$. Electively, the chest was frequently left open, and delayed sternal closure was performed 2 to 3 days later.

\section{Echocardiographic evaluation and follow-up}

We recorded the clinical and echocardiographic data for the patients preoperatively, early postoperative, 6 months postoperative, then every year until their last documented follow-up appointment.

All patients were examined regularly after hospital discharge by a pediatric cardiologist using two-dimensional echocardiography, pulse Doppler and color flow mapping. The ventricular function, degree of regurgitation/ 
stenosis of truncal and pulmonary valves, and any residual defects were assessed. Pressure gradients across the tricuspid valve, the aorta, the conduit, and PAs were also measured. RV pressure of more than $70 \%$ of systematic pressure represented an indication for reintervention.

\section{Statistical analysis}

Continuous data were presented as mean and standard deviation and categorical data as number and percent. Negative binomial regression was used to identify factors affecting the length of hospital stay. Kaplan and Meier's curve was used to describe the survival distribution and freedom from reoperation. Variables affecting reoperation and mortality were tested using multivariable Cox regression analysis with proportional assumption tested using Schoenfeld residual method. Statistical analysis was performed using Stata 14.2 (Stata Corp, College Town, Texas, USA).

\section{Results}

\section{Preoperative and operative data}

Thirty-six patients had truncus arteriosus repair during the study period. There were 21 male patients (58.33\%). Twenty-five patients had type I truncus (69.44\%), 7 patients had type II (19.44\%), 4 patients had type III (11.11\%). Aortic homograft was used in 2 patients (5.56\%) and Contegra in 34 patients (94.44\%). Deep hypothermic circulatory arrest (DHCA) was used in one patient for the repair of the interrupted aortic arch. (Table 1).

Seven patients underwent truncal valve repair during their initial surgery; six of them had truncal valve regurgitation. The degree of regurgitation was severe in two patients and moderate in five. The seventh patient had moderate truncal valve stenosis and moderate regurgitation. All repairs were successful, and follow up echocardiography showed competent arterio-ventricular valves, and no reintervention was required later for valverelated problems.

\section{Early operative outcomes}

Thirty-one patients had open sternum post-repair, and two patients required extracorporeal membrane oxygenation (ECMO). Bleeding occurred in 15 patients (41.67\%), and operative mortality occurred in 5 patients (14.7\%). Postoperative outcomes are presented in Table 2. Patients with truncus arteriosus type 2 and 3 had a longer hospital stay. (Table 3).

\section{Reoperation and survival}

Surgical intervention was required in 8 patients (22.86\%), and 11 patients $(30.56 \%)$ had catheter-based reintervention.
Table 1 Preoperative and operative data. (Continuous variables are presented as mean and standard deviation and categorical data as number and percent)

\begin{tabular}{|c|c|}
\hline Variables & $N=36$ \\
\hline Male & $21(58.33 \%)$ \\
\hline Age (days) & $188.5 \pm 479.567$ \\
\hline Weight (Kg) & $4.612 \pm 4.395$ \\
\hline Height (cm) & $54.676 \pm 14.068$ \\
\hline BSA & $0.265 \pm 0.152$ \\
\hline \multicolumn{2}{|l|}{ Associated anomalies } \\
\hline ASD & $2(5.56 \%)$ \\
\hline Interrupted aortic arch & $1(2.78 \%)$ \\
\hline Hypoplastic pulmonary arteries & $1(2.78 \%)$ \\
\hline Pulmonary artery stenosis & $1(2.78 \%)$ \\
\hline DORV & $1(2.78 \%)$ \\
\hline Previous intracardiac repair & $3(8.33 \%)$ \\
\hline Preop pulmonary hypertensive crises & $10(27.78 \%)$ \\
\hline Preoperative ventilation & $8(22.22 \%)$ \\
\hline \multicolumn{2}{|l|}{ Syndromes } \\
\hline Di George's & $8(22.86 \%)$ \\
\hline CHARGE & $1(2.86 \%)$ \\
\hline Adams-Oliver & $1(2.86 \%)$ \\
\hline \multicolumn{2}{|l|}{ Type of the truncus } \\
\hline Type 1 & $25(69.44 \%)$ \\
\hline Type 2 & $7(19.44 \%)$ \\
\hline Type 3 & $3(8.33 \%)$ \\
\hline Type 4 & $1(2.78 \%)$ \\
\hline \multicolumn{2}{|l|}{ Preoperative truncal valve regurgitation } \\
\hline Mild & $14(38.89 \%)$ \\
\hline Moderate & $6(16.67 \%)$ \\
\hline Severe & $2(5.56 \%)$ \\
\hline Prenatal diagnosis & $2(5.56 \%)$ \\
\hline CPB time (min) & $104.059 \pm 29.435$ \\
\hline Ischemic time (min) & $78.394 \pm 23.285$ \\
\hline \multicolumn{2}{|l|}{ Conduit type } \\
\hline Aorta homograft & $2(5.56 \%)$ \\
\hline Contegra & 34 (94.44\%) \\
\hline
\end{tabular}

$A S D$ atrial septal defect, $B S A$ body surface area, $C P B$ cardiopulmonary bypass, DORV double outlet right ventricle

(Table 4) Freedom from reintervention was $86 \%$ at 1 year, $75 \%$ at 2 years and $65 \%$ at 3 years. (Fig. 1 ).

We reported seven deaths, five of them were in the hospital. The causes of death were a septic shock in three cases, and two cases had a cardiac arrest, and ECMO was instituted as a part of ECPR, both patients did not survive to discharge due to multi-organ failure. We reported two late mortalities, and the cause of death 
Table 2 Postoperative outcomes. (Continuous variables are presented as mean and standard deviation and categorical data as number and percent)

\begin{tabular}{ll}
\hline Variables & $N=34$ \\
\hline Postoperative length of stay (days) & $28.727 \pm 23.753$ \\
Operative mortality & $5(14.7 \%)$ \\
Stroke & $1(2.78 \%)$ \\
Cardiopulmonary arrest & $7(19.44 \%)$ \\
Complete heart block & $1(2.78 \%)$ \\
Bleeding & $15(41.67 \%)$ \\
Pneumonia & $10(27.78 \%)$ \\
Post discharge mortality & $2(5.71 \%)$ \\
Cardiac re-hospitalization & $8(22.87 \%)$ \\
ECMO & $2(5.56 \%)$ \\
Open sternum & $31(86.11 \%)$ \\
ICU stay & $24.029 \pm 21.936$ \\
Intracranial hemorrhage & $1(2.78 \%)$ \\
Mechanical ventilation (days) & $7.59 \pm 6.359$ \\
Inotropic score & $16.35 \pm 8.98$ \\
\hline
\end{tabular}

ECMO extracorporeal membrane oxygenation, ICU intensive care unit

for those patients was not defined. Survival at 1 year was $81 \%$ and at 3 years was $76 \%$. (Fig. 2).

High postoperative inotropic score predicted mortality; however, none of the preoperative and operative variables predicted the need for reoperation. (Table 5).

\section{Discussion}

Complete one stage repair is the treatment of choice for TA and should be performed early within the first few months of life.1 Staged repair of TA was described in association with other anomalies [16]. All our patients had single-stage repair with the repair of concomitant

Table 3 Negative binomial regression for factors affecting the length of hospital stay

\begin{tabular}{llll}
\hline Hospital stay & Coef. & $p$-value & $95 \% \mathrm{Cl}$ \\
\hline Age & 0.0002 & 0.458 & $-0.0006-0.0003$ \\
Gender & -0.009 & 0.955 & $-0.336-0.317$ \\
Weight & 0.003 & 0.915 & $-0.046-0.0514$ \\
Syndrome & 0.190 & 0.326 & $-0.190-0.570$ \\
Type of truncus arteriosus & & & \\
$\quad \mathbf{2}$ vs. $\mathbf{1}$ & 0.526 & 0.008 & $0.135-0.918$ \\
$\mathbf{3}$ vs. $\mathbf{1}$ & 1.152 & 0.001 & $0.499-1.806$ \\
$\mathbf{4}$ vs. $\mathbf{1}$ & -0.212 & 0.636 & $-1.09-0.666$ \\
$\quad$ Pulmonary hypertension crises & -0.131 & 0.483 & $-0.498-0.235$ \\
Preoperative ventilation & 1.197 & $<0.001$ & $0.844-1.55$ \\
\hline
\end{tabular}

Table 4 Re-intervention. (Continuous variables are presented as mean and standard deviation and categorical data as number and percent)

\begin{tabular}{ll}
\hline Reoperation & $8(22.86 \%)$ \\
Diaphragmatic plication & $1(12.5 \%)$ \\
Redo RV-PA conduit replacement and PA plasty & $4(37.50 \%)$ \\
Re-exploration & $2(25 \%)$ \\
RV-PA conduit & $1(12.5 \%)$ \\
Pulmonary artery plasty & $1(12.5 \%)$ \\
Catheter-based reintervention & $11(30.56 \%)$ \\
Diagnostic & $2(18.18 \%)$ \\
VSD closure & $1(9.09 \%)$ \\
ASD closure & $1(9.09 \%)$ \\
Balloon dilatation of the LPA and RPA & $1(9.09 \%)$ \\
RPA stenting & $1(9.09 \%)$ \\
Bilateral PA balloon dilatation + stenting & $2(18.18 \%)$ \\
LPA stenting & $1(9.09 \%)$ \\
Balloon dilatation of the Left main bronchus & $1(9.09 \%)$ \\
MPA-LPA junction stenting & $1(9.09 \%)$ \\
PA stenting & $1(9.09 \%)$ \\
\hline
\end{tabular}

$A S D$ atrial septal defect, $L P A$ left pulmonary artery, MPA main pulmonary artery, $P A$ pulmonary artery, $R P A$ right pulmonary artery, $R V$ right ventricle, $V S D$ ventricular septal defect

anomalies; one patient underwent DHCA for the concomitant repair of the interrupted aortic arch.

Operative mortality was reported in 5 patients (14.7\%), and survival at one-year was $81 \%$. Tlaskal and associates reported $23 \%$ early mortality, and Schrieber and colleagues had $21 \%$ early mortality, which improved to $13 \%$ in the recent era $[1,17]$. The highest mortality after TA repair was reported to occur in the first-year post-repair. Rajasinghe and associates [18] reported 56\% of deaths that occur after TA were in the first year, and Brizard and colleagues [19] had $87 \%$ of deaths that occurred in the first-year post-repair.

Several risk factors were associated with mortality. Several studies demonstrated the association between mortality and IAA $[19,20]$. In our series, one patient had IAA and was discharged after the successful repair of TA and the associated IAA. In other series, ECMO was a risk factor for operative mortality [21]. In this study, two patients had ECMO, and both of them died [22, 23]. Naimo and colleagues [24] found that $32 \%$ of DiGeorge syndrome had operative mortality; similarly, in our study, $25 \%$ of DiGeorge syndrome had operative mortality. All patients who had mortality were males.

Reoperation is common after TA repair, and the freedom from the reoperation in our series was $65 \%$ at 3 years. Naimo and his group in their 35 years' experience 


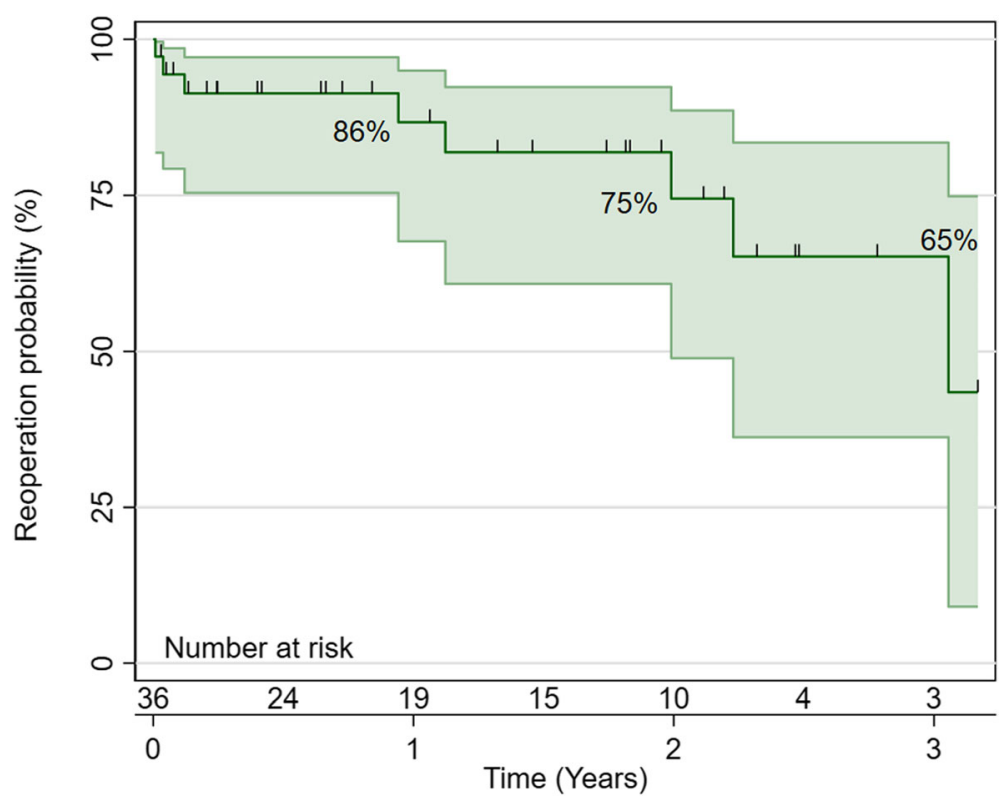

Fig. 1 Reoperation free survival, freedom from reintervention was $86 \%$ at 1 year, $75 \%$ at 2 years and $65 \%$ at 3 years

at Melbourne University, reported freedom from reoperation was $23 \%$ at 10 years [24]. The same group from Melbourne found that reoperations after TA repair were not related to the preoperative truncal valve regurgitation [25]. None of our patients had reoperation for the truncal valve lesion. In other series, the freedom from reoperation for the truncal valve was $83.9 \%$ at 15 years [26].

We had 19 reinterventions, either surgical or catheterbased most of them were related to pulmonary artery stenosis. Similar to other series, which reported reoperation for RVOT obstruction and arch obstruction $[26,27]$. Several techniques were described to decrease the RVOT reoperation [28]. IAA was associated with a high reoperation rate because of arch obstruction; we had one patient with IAA who did not require further reoperation.

\section{Study limitations}

The major limitation of the study is the retrospective nature; however, it is an accepted study design for this rare anomaly. The number of patients is relatively

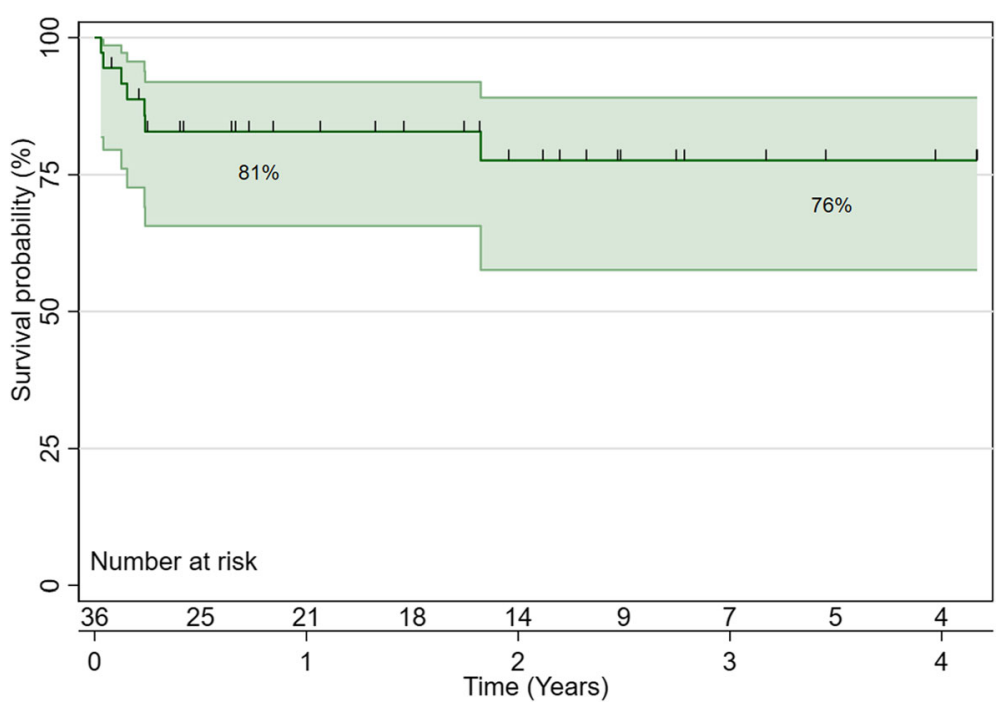

Fig. 2 Kaplan-Meier survival distribution Survival at 1 year was $81 \%$ and at 3 years was $76 \%$ 
Table 5 Multivariable Cox regression for factors affecting reoperation and mortality

\begin{tabular}{llll}
\hline Reoperation & $\mathrm{HR}$ & $p$-value & $95 \% \mathrm{Cl}$ \\
\hline Age & 0.999 & 0.763 & $0.992-1.006$ \\
Gender & 0.316 & 0.222 & $0.05-2.004$ \\
Weight & 0.858 & 0.618 & $0.471-1.564$ \\
Syndrome & 0.849 & 0.855 & $0.147-4.922$ \\
Truncal valve regurgitation & 0.321 & 0.206 & $0.055-1.87$ \\
Truncal valve stenosis & 0.772 & 0.342 & $0.452-1.318$ \\
Type of truncus arteriosus & 1.550 & 0.433 & $0.518-4.637$ \\
Pulmonary artery plasty & 0.312 & 0.234 & $0.046-2.126$ \\
Mortality & & & \\
$\quad$ Age & 1.004 & 0.290 & $0.996-1.013$ \\
$\quad$ Weight & 0.936 & 0.772 & $0.598-1.467$ \\
$\quad$ Truncus arteriosus type & 10.393 & 0.210 & $0.267-404.788$ \\
$\quad$ Associated syndromes & 0.413 & 0.544 & $0.023-7.192$ \\
$\quad$ Truncal valve regurgitation & 1.364 & 0.641 & $0.37-5.032$ \\
Truncal valve stenosis & 0.885 & 0.800 & $0.34-2.266$ \\
$\quad$ Postoperative VIS & 1.137 & 0.013 & $1.028-1.259$ \\
\hline
\end{tabular}

small patients' number with a small number of events.

\section{Conclusion}

Repair of the truncus arteriosus can be performed safely with low morbidity and mortality, both in neonates, infants, and older children. Re-intervention is common, preferably through a transcatheter approach.

\section{Abbreviations}

TA: Truncus arteriosus; VSD: Ventricular septal defect; IAA: Interrupted aortic arch; (RV-PA): Right ventricle to pulmonary artery; PVR: Pulmonary vascular resistance; PA: Pulmonary artery; ECMO: Extracorporeal membrane oxygenation; VIS: Vasoactive inotropic score; ICU: Intensive Care Unit; PVRi: Pulmonary vascular resistance index; CPB: Cardiopulmonary Bypass; RV: Right ventricle; RVOT: Right Ventricular Outflow Tract; DHCA: Deep hypothermic circulatory arrest

\section{Acknowledgments}

The authors gratefully acknowledge, DSR technical and financial support.

\section{Authors' contributions}

Alamri R: Conducted the literature search, data collection, and drafted the manuscript, Dohain A: Designed the study, analysis, and interpretation of data and drafted the manuscript. Arafat A: Conducted the statistical analysis and interpretation of data, and drafted the manuscript, Elmahrouk $A$ : Involved in the study design, analysis, and interpretation of data and drafted the manuscript "corresponding author", Ghunaim A: Data Collection, conducted the literature search, Elassal A: Data Collection, conducted the literature search, Jamjoom A: Supervised the study and conducted the review of data, Al-Radi O: Designed the study, analysis, and interpretation of Data, Supervised the study. The author(s) read and approved the final manuscript.

\section{Funding}

This project was funded by the Deanship of Scientific Research (DSR), King Abdulaziz University, Jeddah, under grant no. (DF-795-140-1441).

\section{Availability of data and materials}

General data are part of the Congenital Cardiac Surgery Database (CCSdb) available at www.ccsdb.org and were populated prospectively. Specific data and materials are available with the corresponding author.

\section{Ethics approval}

The study was approved by the Institutional Review Board Committee of King Abdulaziz University, Jeddah, Saudi Arabia. The need for informed consent was waived due to the retrospective nature of the study. Patients' confidentiality was maintained, removing any identifying information from the data set by the data controller before further usage and analysis. The data both variables and their values were coded into Alpha-numeric format for concealment with few designated persons having the coding key.

\section{Consent for publication}

Not Applicable.

\section{Competing interests}

The authors declare that they have no competing interests.

\section{Author details}

${ }^{1}$ Cardiac Surgery Division, Department of Surgery, King Abdulaziz University, Jeddah, Saudi Arabia. ${ }^{2}$ Pediatric Cardiology Division, Department of Pediatrics, King Abdulaziz University, Jeddah, Saudi Arabia. ${ }^{3}$ Pediatric Cardiology Division, Department of Pediatrics, Cairo University, Giza, Egypt. ${ }^{4}$ Department of Cardiothoracic Surgery, Tanta University, Tanta, Egypt. ${ }^{5}$ Department of Cardiothoracic Surgery, King Faisal Specialist Hospital and Research Centre, Jeddah, Saudi Arabia. ${ }^{6}$ Department of Cardiothoracic Surgery, Zagazig University, Zagazig, Egypt.

Received: 29 November 2019 Accepted: 27 April 2020

Published online: 11 May 2020

\section{References}

1. Tlaskal T, Chaloupecky V, Hucin B, Gebauer R, Krupickova S, Reich O, Skovranek J, Tax P. Long-term results after correction of persistent truncus arteriosus in 83 patients. Eur J Cardiothorac Surg. 2010;37(6):1278-84. https://doi.org/10.1016/j.ejcts.2009.12.022.

2. Hanley FL, Heinemann MK, Jonas RA, Mayer JE Jr, Cook NR, Wessel DL, Castaneda AR. Repair of truncus arteriosus in the neonate. J Thorac Cardiovasc Surg. 1993;105(6):1047-56.

3. Morgan CT, Tang A, Fan CP, Golding F, Manlhiot C, van Arsdell G. Honjo O and Jaeggi E:contemporary outcomes and factors associated with mortality after a fetal or postnatal diagnosis of common arterial trunk. Can J Cardiol. 2019;35(4):446-52. https://doi.org/10.1016/j.cjca.2018.12.006.

4. McGoon DC, Rastelli GC, Ongley PA. An operation for the correction of truncus arteriosus. JAMA. 1968:205(2):69-73.

5. Ebert PA, Turley K, Stanger P, Hoffman JI, Heymann MA, Rudolph AM. Surgical treatment of truncus arteriosus in the first 6 months of life. Ann Surg. 1984;200(4):451-6. https://doi.org/10.1097/00000658-198410000-00006.

6. Russell HM, Pasquali SK, Jacobs JP, Jacobs ML, O'Brien SM, Mavroudis C, Backer $\mathrm{CL}$. Outcomes of repair of common arterial trunk with truncal valve surgery: a review of the society of thoracic surgeons congenital heart surgery database. Ann Thorac Surg. 2012;93(1):164-9; discussion 169. https://doi.org/10.1016/j.athoracsur.2011.04.121.

7. Thompson LD, McElhinney DB, Reddy M, Petrossian E, Silverman NH, Hanley FL. Neonatal repair of truncus arteriosus: continuing improvement in outcomes. Ann Thorac Surg. 2001;72(2):391-5. https://doi.org/10.1016/ s0003-4975(01)02796-5.

8. Brown JW, Ruzmetov M, Okada Y, Vijay P, Turrentine MW. Truncus arteriosus repair: outcomes, risk factors, reoperation and management. Eur J Cardiothorac Surg. 2001;20(2):221-7. https://doi.org/10.1016/s10107940(01)00816-8.

9. Kaza AK, Burch PT, Pinto N, Minich LL, Tani LY, Hawkins JA. Durability of truncal valve repair. Ann Thorac Surg. 2010;90(4):1307-12; discussion 1312 https://doi.org/10.1016/j.athoracsur.2010.06.018.

10. Jacobs JP, O'Brien SM, Pasquali SK, Jacobs ML, Lacour-Gayet FG, Tchervenkov Cl, Austin EH 3rd, Pizarro C, Pourmoghadam KK, Scholl FG, Welke KF, Mavroudis C. Variation in outcomes for benchmark operations: an analysis of the Society of Thoracic Surgeons Congenital Heart Surgery 
Database. Ann Thorac Surg. 2011;92(6):2182-4. https://doi.org/10.1016/j. athoracsur.2011.06.008.

11. Mastropietro CW, Amula V, Sassalos P, Buckley JR, Smerling AJ, lliopoulos I, Riley CM, Jennings A, Cashen K, Narasimhulu SS, Narayana Gowda KM, Bakar AM, Wilhelm M, Badheka A, Moser EAS, Costello JM. CONGENITAL : TRUNCUS ARTERIOSUS Characteristics andoperative outcomes for children undergoing repair of truncus arteriosus : A contemporary multicenter analysis. J Thorac Cardiovasc Surg. 2019;157(6):2386-2398.e4. https://doi.org/ 10.1016/j.jtcvs.2018.12.115.

12. Buckley JR, Amula V, Sassalos P, Costello JM, Smerling AJ, lliopoulos I, Jennings A, Riley CM, Cashen K, Suguna Narasimhulu S, Gowda KMN, Bakar AM, Wilhelm M, Badheka A, Moser EAS. Mastropietro CW; collaborative research in pediatric cardiac intensive care investigators: multicenter analysis of early childhood outcomes after repair of truncus. Ann Thorac Surg. 2019; 107(2):553-9. https://doi.org/10.1016/..athoracsur.2018.08.094.

13. Poynter JA, Eghtesady P, McCrindle BW, Walters HL III, Kirshbom PM, Blackstone EH, Husain SA, Overman DM, Austin EH, Karamlou T, Lodge AJ, St. Louis JD, Gruber PJ, Ziemer G, Davies RR, Jacobs JP, Brown JW, Williams WG, Tchervenkov Cl, Jacobs ML, Caldarone CA, for the Congenital Heart Surgeons' Society. Association of Pulmonary Conduit Type and Size With Durability in Infants and Young Children. Ann Thorac Surg. 2019;96(5):1695702. https://doi.org/10.1016/j.athoracsur.2013.05.074.

14. Chen Q, Gao H, Hua Z, Yang K, Yan J, Zhang H, Ma K, Zhang S, Qi L, Li S. Outcomes of surgical repair for persistent truncus arteriosus from neonates to adults: a single Center's experience. PLoS One. 2016;11(1):e0146800. https://doi.org/10.1371/journal.pone.0146800.

15. Williams JM, de Leeuw M, Black MD, Freedom RM, Williams WG, McCrindle BW. Factors associated with outcomes of persistent truncus arteriosus. J Am Coll Cardiol. 1999;34(2):545-53. https://doi.org/10.1016/s07351097(99)00227-2.

16. He D, Olivieri LJ, Jonas RA, Sinha P. Palliation of truncus arteriosus associated with complete Atrioventricular Canal--results of single ventricle palliation. World J Pediatr Congenit Heart Surg. 2015;6(4):663-6. https://doi. org/10.1177/2150135115578180.

17. Schreiber C, Eicken A, Balling G, Wottke M, Schumacher G, Paek SU, Meisner $\mathrm{H}$, Hess J, Lange R. Single centre experience on primary correction of common arterial trunk: overall survival and freedom from reoperation after more than 15 years. Eur J Cardiothorac Surg. 2000;18(1):68-73. https://doi. org/10.1016/s1010-7940(00)00449-8.

18. Rajasinghe HA, McElhinney DB, Reddy VM, Mora BN, Hanley FL. Long-term follow-up of truncus arteriosus repaired in infancy: a twenty-year experience. J Thorac Cardiovasc Surg. 1997;113:869-79.

19. Brizard CP, Cochrane A. Austin, C Nomura F and Karl TR: management strategy and long-term outcome for truncus arteriosus. Eur I Cardiothorac Surg. 1997;11:687-96.

20. McCrindle BW, Tchervenkov Cl, Konstantinov IE, Williams WG, Neirotti RA, Jacobs ML, Blackstone EH. Congenital Heart Surgeons Society: Risk factors associated with mortality and interventions in 472 neonates with interrupted aortic arch: A Congenital Heart Surgeons Society study. J Thorac Cardiovasc Surg. 2005;129:343-50

21. Naimo PS, Fricke TA, Yong MS, d'Udekem Y, Kelly A, Radford DJ, Bullock A, Weintraub RG, Brizard CP, Konstantinov IE. Outcomes of Truncus Arteriosus Repair in Children: 35 Years of Experience From a Single Institution. Semin Thorac Cardiovasc Surg. 28(2):500-11.

22. Elmahrouk AF, Ismail MF, Hamouda T, Shaikh R, Mahmoud A, Shihata MS, Alradi $\mathrm{O}$, Jamjoom A. Extracorporeal membrane oxygenation in postcardiotomy pediatric patients-15 years of experience outside Europe and North America. Thorac Cardiovasc Surg. 67(1):28-36.

23. Dohain AM, Abdelmohsen G, Elassal AA, Elmahrouk AF, Al-Radi OO. Factors affecting the outcome of extracorporeal membrane oxygenation following paediatric cardiac surgery. Cardiol Young. 2019;29(12):1501-9.

24. Naimo PS, Fricke TA, d'Udekem Y, Brink J, Weintraub RG, Brizard CP, Konstantinov IE. Impact of truncal valve surgery on the outcomes of the truncus arteriosus repair. Eur J Cardiothorac Surg. 2018:54(3):524-31. https:// doi.org/10.1093/ejcts/ezy080.

25. Ivanov Y, Mykychak Y, Fedevych O, Motrechko O, Kurkevych A, Yemets I. Single-Centre 20- year experience with repair of truncus arteriosus. Interact Cardiovasc Thorac Surg. 2019;29(1):93-100. https://doi.org/10.1093/icvts/ ivz007.

26. Naimo PS, Fricke TA, Lee MGY, d'Udekem Y, Brink J, Weintraub RG, Brizard $\mathrm{CP}$, Konstantinov IE. Long-term outcomes following repair of truncus arteriosus and interrupted aortic arch [published online ahead of print, 2019 Jun 17]. Eur J Cardiothorac Surg. 2019:ezz176. https://doi.org/10.1093/ejcts/ ezz176.

27. Louis C, Swartz MF, Simon BV, Cholette JM, Atallah-Yunes N, Wang H, Gensini F, Alfieris GM. Modified repair of type I and II truncus arteriosus limits early right ventricular outflow tract reoperation. Semin Thorac Cardiovasc Surg. 2018;30(2):199-204. https://doi.org/10.1053/j.semtcvs.2018. 02.003.

28. Arafat AA, Elatafy EE, Elshedoudy S, Zalat M, Abdallah N, Elmahrouk A. Surgical strategies protecting against right ventricular dilatation following tetralogy of Fallot repair. J Cardiothorac Surg. 2018;13(1):14.

\section{Publisher's Note}

Springer Nature remains neutral with regard to jurisdictional claims in published maps and institutional affiliations.
Ready to submit your research? Choose BMC and benefit from:

- fast, convenient online submission

- thorough peer review by experienced researchers in your field

- rapid publication on acceptance

- support for research data, including large and complex data types

- gold Open Access which fosters wider collaboration and increased citations

- maximum visibility for your research: over $100 \mathrm{M}$ website views per year

At BMC, research is always in progress.

Learn more biomedcentral.com/submissions 